\title{
Dificuldades e facilidades vividas pelos docentes no processo de implantação do currículo integrado no curso de Enfermagem da Universidade Estadual De Londrina
}

\author{
Good and bad experiences along the implementation process of the Integrated \\ Curriculum of the Nursing School at the StateUniversity of Londrina
}

\author{
Christine Baccarat de Godoy ${ }^{1}$; Nadia Aparecida de Souza ${ }^{22}$
}

\begin{abstract}
Resumo: O estudo teve como objetivo determinar as perspectivas e dificuldades dos docentes do Departamento de Enfermagem do Centro de Ciências da Saúde, da Universidade Estadual de Londrina, na construção e implantação do Módulo I, do Currículo Integrado de Enfermagem. A pesquisa se constituiu em um Estudo de Caso e os dados foram obtidos através de questionário aplicado a 13 (treze) docentes que construíram e implementaram o Módulo I, no ano de 2000. A análise dos dados possibilitou determinar os fatores facilitadores e dificultadores na implementação do processo, bem como, levantar a percepção dos docentes sobre o processo de mudança curricular. Dentre os fatores facilitadores, destacaram-se o empenho do Colegiado de Curso, o apoio da direção do CCS, o trabalho coletivo em torno de um mesmo ideal, a união, dedicação, compromisso e cooperação entre os professores e o desejo de inovar e criar frente à responsabilidade de formar um profissional consciente, crítico, criativo e reflexivo. Em contrapartida, a carência de tempo devido às atividades docentes e administrativas, a escassez de recursos materiais e humanos e a precariedade da estrutura física, foram mencionados como fatores dificultadores. A avaliação dos docentes também apontou a importância da formação pedagógica continuada. O estudo, ao fornecerem indicadores de mudança, contribuem para a melhoria da qualidade do ensino na consecução do novo currículo de Enfermagem da Universidade Estadual de Londrina.
\end{abstract}

Palavras-chave: enfermagem, currículo integrado, educação em enfermagem, mudança curricular na enfermagem, transformação curricular.

Abstract: The purpose of this study was to determine the perspectives and difficulties faced by the teachers from the
Nursing Department at the Health Sciences Center at the State University of Londrina during Module I development and
implementation of the Integrated Curriculum of the Nursing School. The research was made up of a case study and the
data were obtained through a set of questions answered by 13 (thirteen) teachers, who designed and established the
Module I of the Integrated Curriculum of the Nursing School at the State University of Londrina in 2000 . The data analysis
made it possible to determine the factors which either made it difficult or easy to implement the process as well as to
arise the professors' perception of curriculum changes. The study has contributed, so far, to the teaching quality
improvement of the new Nursing School Curriculum at the State University of Londrina. Key words: nursing, integrated curriculum, nursing education, curricular modification in nursing school, implementation of a new curriculum.

\section{Introdução}

Atualmente, o mercado de trabalho tem exigido uma mudança na formação e exercício profissional, o que vem demandando, por parte das escolas, mudanças em seus currículos e em suas práticas pedagógicas.

Nesse contexto, o Curso de Enfermagem, da Universidade Estadual de Londrina, compreendendo por currículo "[...] não só o conjunto das disciplinas lecionadas, mas a totalidade das experiências educativas patrocinadas pela escola" (FONTOURA, 1972, p.28) e preocupado em formar profissionais críticos, reflexivos, dotados de competência técnica e política para atuar significativamente e transformar a
Quando você olha uma parede levantada, pronta, consegue ver nela o valor do teu trabalho? Você percebe que a massa que você preparou tá aí dentro, sustentando tudo, que tuas mãos construíram isso? Percebe? (PECCI, 1990, p.41).

realidade social, implantou em janeiro de 2000, o CurRículo InTEGRADO do CuRSO de EnFERMAGEM, pautandose nos princípios propostos pela nova Lei de Diretrizes e Bases da Educação Nacional - Lei n. 9.394/96.

O Curso de Graduação em Enfermagem, da Universidade Estadual de Londrina, foi implantado em 1972, tem passado por sucessivas reformulações curriculares, resultantes, sempre, de amplas discussões e reflexões, orientadas pelo compromisso com a melhoria da qualidade de ensino e da prestação dos serviços de saúde à população (UEL, 1999, p.3).

Em conseqüência, o compromisso com a formação de um profissional sintonizado com o (re)direcionamento

\footnotetext{
1 Enfermeira Especialista em Metodologia da Ação Docente pela Universidade Estadual de Londrina, docente do Departamento de Enfermagem da Universidade Estadual de Londrina.

2 Doutora em Educação pela Universidade Estadual Paulista, docente do Departamento de Educação da Universidade Estadual de Londrina e integrante do Núcleo de Estudos e Pesquisas em Avaliação Educacional.
} 
da política de saúde e com as variações no perfil epidemiológico, tornou necessária a elaboração e implementação de uma proposta inovadora, que contemplasse não somente a grade curricular, mas que investisse em uma perspectiva pedagógica que permitisse uma ação educativa mais global e mais crítica.

A nova proposta curricular, cuja estrutura segue a criação de módulos integrados que viabilizam a interdisciplinaridade e a relação teoria-prática, adotando a Metodologia da Problematização, propõe a formação de um profissional capaz de "[...] prestar e gerenciar a assistência de enfermagem com conhecimentos, habilidades e atitudes que poderão influenciar nas decisões políticas e organizacionais na área de saúde" (UEL, 1999, p.3).

\section{Fundamentos Teóricos}

A filosofia desta concepção de ensino converge para a construção dos conhecimentos pelo aluno ao longo de sua vida acadêmica, preparando-o para o exercício profissional fundamentado em reflexão profunda, análise crítica, capacidade de tomada de decisões e competência na resolução de problemas de forma crítica e integrada à realidade social e profissional (UEL, 1999).

Baseado em concepção crítico-social e respaldado em pedagogia problematizadora, esta proposta veio romper com o ensino tradicional, marcado pela passividade e falta de atitude crítica do aluno, bem como pela distância entre teoria e prática, condicionantes que trazem para o cotidiano, quer na prática profissional, quer no exercício da cidadania, conseqüências como conformismo, submissão à dominação, individualismo, falta de participação e adoção indiscriminada de modelos de pensamento (DIAZ BORDENAVE, 1983).

Conseqüentemente, o processo de ensino deve desenvolver no aluno o seu potencial político-social, juntamente com o seu potencial intelectual, promovendo o pleno desenvolvimento de seus saberes teóricos e práticos para o exercício profissional, formando o indivíduo como sujeito autônomo e livre (FLEURI, 1997) e fazendo da educação uma responsabilidade social e política (FREIRE, 1971). A prática pedagógica, portanto, no contexto da nova proposta, longe de reproduzir o já existente, cumpre colaborar para a "[...] transformação capaz de trazer melhores condições de vida para o homem em sociedade" (BERBEL, 1996, p.38).

No interior da nova proposta curricular evidencia-se que a metodologia tradicional, eminentemente dedutiva, baseada na reprodução de conceitos e noções, tendo o professor como detentor absoluto do saber e tendo o real como algo a ser explicado e não transformado, rompe-se frente a uma metodologia indutiva, na qual a prática social dos educandos é que constitui o eixo em torno do qual gira o processo educativo, aprofundando, progressiva e continuadamente, o conhecimento do real e as suas possibilidades de transformação.

\section{Problema}

A implantação da nova proposta educacional, desse modo, exigiu alterações profundas - conceituais e práticas - de todos os envolvidos, tornando necessário avaliar o impacto dessas transformações no cotidiano acadêmico e naqueles que dele participam. Que fatores ou condições os professores indicam como dificultadores e facilitadores na implementação da nova proposta pedagógica?

\section{Objetivos}

Assim, esse estudo tem por meta: determinar e analisar as dificuldades e facilidades vivenciadas pelos docentes do Departamento de Enfermagem, do Centro de Ciências da Saúde, da Universidade Estadual de Londrina, na construção e implantação do Módulo I, do CurRículo INTEGRado do Curso de Enfermagem, fornecendo indicadores, em conseqüência, que auxiliem em seu aprimoramento constante.

\section{Metodologia \\ 5.1 Natureza do estudo}

A pesquisa desenvolvida - um estudo de caso pretendeu permitir uma abordagem qualitativa do processo de construção e implementação do Módulo I, do Currículo Integrado do Curso de Enfermagem, principalmente porque se fazia premente captar a experiência vivida pelos docentes, uma vez que "[...] uma situação humana só é caracterizável quando se tomam em consideração as concepções que os participantes têm dela" (MINAYO, 1992, p.33).

\subsection{População e campo de estudo}

A presente pesquisa foi realizada junto aos treze docentes responsáveis pela elaboração e implementação do Módulo I, do Currículo INTEGRado do Curso de Enfermagem, envolvendo, portanto, o Departamento de Enfermagem, Departamento Materno Infantil e Saúde Comunitária, mediante autorização formal do Colegiado do Curso de Enfermagem

\subsection{Coleta de dados e instrumento}

Os dados foram obtidos a partir de questionário cuidadosamente elaborado e organizado no intuito de contemplar diferentes aspectos relativos não somente ao processo de elaboração do módulo, como também sua consecução, no decorrer dos meses de fevereiro a abril de 2000. Assim, sua forma final apresentou:

a) PARTE I: dados de identificação, com informações sobre regime de trabalho do docente, nível na instituição, TIDE (tempo integral de dedicação exclusiva que o docente recebe quando vinculado a um projeto de pesquisa), tempo de docência na Universidade Estadual de Londrina e disciplina que ministra; 
b) PARTE II: dados sobre a formação acadêmica do docente quanto à graduação, pós-graduação, mestrado e doutorado;

c) PARTE III: perguntas relativas aos objetivos do estudo e se compõe por 12 (doze) questões fechadas e 9 (nove) questões abertas, as quais possibilitaram aos docentes expressarem sua percepção e avaliação quanto ao currículo integrado.

Entregues em julho de 2000, todos os questionários foram respondidos e devolvidos em setembro do mesmo ano.

\subsection{Tratamento dos dados e categorias de análise}

No presente artigo, os dados apresentados versarão sobre as respostas obtidas nas questões abertas, que foram operadas manualmente e agrupadas de acordo com as seguintes categorias de análise: fatores que facilitaram a construção e a implementação do Módulo I; fatores que dificultaram a construção e a implementação do Módulo I; e a importância da formação pedagógica no processo de construção e implementação do novo currículo.

A análise efetiva teve como objetivo 0 aperfeiçoamento da proposta adotada pelo Curso de Enfermagem da Universidade Estadual de Londrina, uma vez que a reflexão permitiu determinar e melhor compreender o processo vivenciado para a elaboração e implementação da nova proposta em sua íntegra, favorecendo a todos melhor vislumbrar os caminhos pelos quais docentes, alunos e profissionais do setor de serviços de saúde vêm avançando.

\section{Tecendo Considerações}

A elaboração do novo currículo do Curso de Enfermagem constituiu um trabalho árduo, que consumiu tempo e esforço, que exigiu dedicação e desprendimento, que demandou comprometimento profissional com a formação de enfermeiros mais competentes, mais cônscios das responsabilidades inerentes ao seu fazer.

Assegurar a consecução de suas metas pressupõe o acompanhamento das realizações efetivadas, das dificuldades vivenciadas e a delimitação das ações futuras a serem implementadas na superação dos problemas que obstaculizam sua concretização no diaa-dia da sala de aula.

Nos depoimentos colhidos, tornou-se evidente que dentre os fatores que facilitaram a construção e implementação do Módulo I, destacou-se a "[...] união entre os professores do básico com os do profissionalizante" (Professor 1, 2, 5, 6, 7, e 10), que vem viabilizando a interdisciplinaridade e a correlação entre teoria e prática, integrando conteúdos que propiciam a aprendizagem de forma mais significativa.

Integrar, dinamicamente, teoria e prática no contexto de uma atuação pedagógica compartilhada e solidária sempre constituiu condição essencial na formação do profissional de enfermagem capaz de atuar em equipe multiprofissional. Assim, a vivência de um trabalho cooperativo, que favorece aos educandos experienciar um processo que thes permita perceber que "[...] a apropriação dos conhecimentos teóricos não se constitui em processo passivo e acrítico, mas em aquisição - fruto de reflexão, elaboração e reelaboração constantes - fundamentada nas necessidades concretas postas pela realidade de vida e de trabalho" (SOUZA, 2000, p.33), é essencial na edificação do perfil do profissional de enfermagem que se pretende formar.

Importante, também, foi "[...] o número de docentes que participaram da implementação" (Professor 4, 5, 6, 7, 8,), a "[...] dedicação, compromisso e cooperação dos professores entre si, na elaboração e na implementação do Módulo I" (Professor 2, 5, 6 e 10), "[...] o empenho do Colegiado de Curso" (Professor 2, 5, 10 e 12), "[...] o apoio da direção do CCS" (Professor 2, 10 e 12), "[...] o desejo de inovar e criar, tendo a responsabilidade de formar um profissional mais consciente de suas responsabilidades". (Professor 12), o "[...] estímulo do grupo para continuar avançando" (Professor 4), a "[...] união do grupo durante o processo de construção do Módulo I, e, mais ainda, durante sua implementação" (Professor 5), o "[...] apoio do Projeto UNI, patrocinando eventos e estimulando a busca de alternativas de ensino mais adequadas à formação do profissional que se deseja ter atuando no setor de saúde" (Professor 9), a "[...] adesão dos docente, que em prejuízo de seu tempo de lazer ou estudo, dedicaram-se à construção e implementação do Módulo l" (Professor 6) e, principalmente, "[...] a vontade de mudar, que fez com que todos abraçassem a nova proposta com muito entusiasmo (Professor 5), juntamente com o "[...] trabalho coletivo em torno de um mesmo ideal" (Professor 6).

União, apoio recíproco, aprofundamento dos laços de interdependência, comprometimento individual e coletivo na edificação do mesmo sonho evidenciaramse enquanto aspectos fundamentais para a construção e implementação do Módulo I. As pessoas se envolveram e ousaram produzir transformações - juntas - pois "[...] somente mediante o esforço e a competência em trabalhar responsável e interativamente em grupos nos tornamos efetivamente produtivos" (MATOS, 1998, p.68).

Assim, o trabalho coletivo possibilitou aprender a administrar conflitos, a criar raízes e a promover a articulação de um com o outro, num internalizar de princípios e num (re)aprender a fazer (MATOS, 1998). O trabalho em grupo favoreceu a cada um e a todos "[...] ser parte, tomar parte e ter parte" (DIAZ BORDENAVE, 1989, p.69), a tornar-se co-responsável pela construção do produto no decorrer do processo.

Mas, sempre que avanços são conquistados, novas dificuldades se interpõem; sempre que inovações são implementadas, entraves burocráticos ou carências estruturais se evidenciam. Assim, os fatores dificultadores enunciados giram em torno da carência de tempo, da escassez de recursos materiais e humanos, da precariedade da estrutura física, progressivamente fragilizada face ao descaso da administração pública. 
Um dos fatores que para os docentes dificultou uma melhor construção e implementação do Módulo I foi [...] "o tempo muito curto" (Professores 1, 3, 4, 5 e 9) e a [...] "sobrecarga de atividades docentes e administrativas" (Professores 1, 2, 5, 5, 9, 11 e 13). Cumpre ressaltar que criar e transformar concepções e ações, mediante as condições do dia-a-dia constitui um desafio grandioso, que muitas vezes terminou por gerar frustração e descontentamento, pois, por maior que seja a disponibilidade e comprometimento dos docentes, ainda assim, eles não conseguem, muitas vezes, superar a falta de tempo e a precariedade das condições de trabalho, tornando difícil, manter vivas [...] "suas crenças e utopias na educação solidária” (PONCE, 1997, p.86).

A disponibilidade de tempo para analisar e avaliar continuadamente as atividades diariamente desenvolvidas é fundamental no contexto da nova proposta, a fim de permitir o re-direcionamento dos processos de ensino e de aprendizagem, bem como para aumentar o comprometimento e o envolvimento de todos, pois o que os professores produzem junto aos alunos a cada novo dia de trabalho decorre da possibilidade de refletirem sobre sua prática conjunta e solidariamente edificada no momento anterior. Só assim, portanto, torna-se possível o aperfeiçoamento do processo e o aperfeiçoar-se no decorrer dele (SOUZA, 2000, p.32). O tempo foi muito pouco,

[...] num contexto que para se metamorfosear, pela construção de uma nova prática EXIGIA a partilha de saberes e fazeres, EXIGIA, ainda, a compreensão dos fundamentos teóricos que conferem clareza quanto ao sentido do processo desencadeado e quanto ao significado do produto edificado pela ação pedagógica e EXIGIA, portanto, nada menos que a superação de práticas acríticas e ingênuas, perpetradas pela reprodução de práticas passadas, fundamentadas no senso comum, pela REFLEXÃo no e sobre os fazeres desenvolvidos (SOUZA, 1999, p. 208).

De forma que, muitas vezes, [...] "a vivência que os professores têm do tempo é de um tempo corrido, tarefeiro, cansativo e estressante, que não abriga a reflexão, a construção de uma identidade profissional mais autônoma, ao contrário, até mesmo a impede" (PONCE, 1997, p.88). Espaços e tempos coletivos são fundamentais para a promoção das condições de elaboração, desenvolvi-mento, análise e aperfeiçoamento de projetos traçados. Espaços e tempos coletivos são essenciais para que os partícipes do processo possam ir, no transcorrer dele, construindo e reconstruindo o próprio saber e o próprio saber na partilha de seus muitos saberes e fazeres, de forma a tornar quase impossível que [...] "não se deixassem contagiar pelo encanto e pelo prazer de ser e fazer parte de um coletivo, de poder contar com os companheiros e companheiras para compartilhar as venturas e desventuras da atividade docente" (GARCIA, 1999, p.78).

Quanto à escassez de recursos, dentre os fatores dificultadores, ainda foram indicados: [...] "recursos humanos insuficientes" (Professores 1, 2, 3, 5, 6, 7, 8, 10, 11 e 13), uma vez que auxiliares administrativos, técnicos de informática, [...], tão necessários, não estavam disponíveis em tempo e número suficientes; [...] "recursos bibliográficos" parcos (Professores 1, 2, 3, 4, 5, 7, 8, 9, $10,12,12)$ - "quer quanto à diversidade e atualidade de títulos, quer quanto ao número de exemplares disponíveis" (Professor 4) - dificultando sobremaneira o desencadear de um processo que visa favorecer atitudes de busca e coleta de informações de maneira autônoma; [...] "estrutura física da biblioteca do Centro de Ciências da Saúde e do Hospital Universitário sem condições de receber todos os alunos" (Professores 2, 4, 5, 6, 8, 9, 11, $12) ;[. .$.$] "estrutura física das salas de aula imprópria"$ quanto à ventilação, iluminação, etc. (Professores 2, 3, 6, 8, 9, 11); impossibilidade da Documentação Científica para atender na produção de materiais didáticos e na disponibilização de recursos de ensino que se faziam fundamentais (Professores 1, 2, 4, 5, 7, 8, 10, 11).

É importante considerar que, frente à nova concepção de ensino, tornou-se imprescindível contar com recursos em quantidade e na qualidade necessárias à viabilização da proposta. Afinal, mudanças curriculares - principalmente dessa magnitude - exigem muito mais do que [...] "vontade de mudar da parte dos professores e dos alunos" (Professor 11), mas, pressupõe estruturação e oferta de serviços de apoio e de recursos humanos e materiais adequados e suficientes, o que não foi possível constatar no decorrer do processo de construção e implementação do Módulo I.

Enfrentar a inquietação que emergia já há algum tempo, exigiu dos professores determinação frente às dificuldades apresentadas neste estudo. Assim, os apontamentos levantados nesta pesquisa nos levam a pleitear por melhorias estruturais, uma vez que o corpo docente necessita de condições favoráveis para promover mudanças significativas.

Na elaboração e implementação da nova proposta pedagógica que fundamenta o CuRRícuLo INTEGRADO DO CuRso de ENFERMAGEM, os docentes deixaram evidente que [...] "a formação continuada é essencial para o enfrentamento das dificuldades e desafios colocados para os professores" (DIAS-DA-SILVA, 1998, p.33).

A formação continuada, assegurada pela promoção de grupos de estudo, de círculos de debate, de encontros para troca de experiências entre os pares, de assessoria pedagógica, [...] tudo isso, enfim, possibilitou que os professores elaborassem e reelaborassem seus [...] "saberes iniciais em confronto com suas experiências práticas, cotidianamente vivenciadas nos contextos escolares" (PIMENTA, 1999, p.29).

A riqueza decorrente do processo vivenciado pelo grupo de professores advém da possibilidade de confronto e de troca de práticas e saberes, facultando, assim, que cada um e todos, contínua e progressivamente, fossem [...] "construindo seus saberes como praticum, ou seja, aquele que constantemente reflete na e sobre 
a prática" (PIMENTA, 1999, p.29). Assim, tendo como ponto de partida que o conhecimento não é algo estagnado e que, ao contrário, cresce à medida que a prática se concretiza mediante a reflexão sobre ela, torna-se necessário [...] "renovar constantemente as práticas em sala de aula, fazendo da reflexão sobre a prática um motor essencial de inovação" (PERRENOUD, 1993, p.185).

As Oficinas de Formação Continuada, com a presença dos docentes, representantes discentes e profissionais dos serviços, para a introdução da mudança curricular (Professores 1, 2, 4, 9, 10 e 12), promovidas pelo Colegiado de Curso, com apoio da Direção de Centro e do Projeto UNI, foram essenciais para a realização da mudança curricular, ao favorecerem o [...] "trabalho coletivo em torno do mesmo ideal" (Professor 10), pelo revivificar da [...] "vontade de construir uma nova maneira de aprender e de ensinar" (Professor 3). A [...] "coesão do grupo foi sendo construída nesses espaços de estudo e discussão coletiva" (Professor 2) e a superação das muitas dificuldades que se enunciaram decorreu, em grande parte, do poder estar com parceiros que compartilhavam das mesmas dúvidas e dos mesmos sonhos.

Assim, a avaliação dos docentes destacou a importância da formação pedagógica, uma vez que concretizar tais mudanças [...] "exige novas concepções, métodos e práticas" (ITO, 1994, p.7) que só ela pode oferecer.

$\mathrm{Na}$ percepção dos docentes, [...] "além de ter norteado toda a mudança curricular" (Professor 5), a formação pedagógica foi [...] "fundamental para o domínio da metodologia de ensino enquanto instrumento básico na introdução das mudanças necessárias" (Professor 6). Para os docentes, portanto, [...] "entender a concepção da proposta foi essencial para que o método não se tornasse uma camisa de força que, longe de auxiliar em sala de aula, impedisse ou dificultasse o desenvolvimento do processo de formação idealizado" (Professor 12). Para tanto, a formação continuada permitiu [...] "(re)ver novas concepções e formas de ser educador e fazer acontecer o processo ensino e aprendizagem" (Professor 9).

Por sua vez, no que concerne à formação continuada, alguns fatores que dificultaram a construção e implementação do módulo, evidenciaram a importância da preparação do docente para a condução do processo de ensino e aprendizagem, pois a [...] "inexperiência de alguns em relação à nova proposta" (Professor 2, 8 e 10), a [...] "falta de domínio da metodologia" (Professor 6) e a [...] "falta de clareza quanto ao transcorrer do processo de ensino e aprendizagem" (Professor 3), impediram um desenrolar mais efetivo da proposta.

Este estudo possibilitou uma análise das dificuldades e facilidades enfrentadas pelos docentes na construção e implementação do Módulo I, do CuRRículo INTEGRADO do Curso de Enfermagem, da Universidade Estadual de Londrina, demonstrando que o aprendizado de uma nova metodologia possibilitou entender que [...] "há outras formas de fazer com que o aluno aprenda de forma mais efetiva" (Professor 3), sendo [...] "possível mudar o perfil do aluno através da postura que o professor adota frente à nova metodologia" (Professor 2), sem desconsiderar [...] "a importância do trabalho em grupo, solidário e responsável" (Professores 5 e 10) e tendo os processos de ensino e aprendizagem como [...] "uma forma de ser educador, de uma maneira mais humana e mais comprometida" (Professor 9), afinal, [...] "as inovações metodológicas são imprescindíveis não apenas nas formas de pensar, mas, principalmente, nas formas de fazer" (CARVALHO; CASTRO, 1985, p.76).

\section{Resultados}

Ao longo deste estudo pudemos melhor compreender o universo das transformações curriculares vivenciadas, em suas limitações e em suas possibilidades, no retomar do primeiro momento dessa caminhada - 0 Módulo I.

Dentre os fatores que facilitaram a construção e implementação do Módulo I do Currículo Integrado de Enfermagem, foram listados a [...] "dedicação, compromisso e cooperação dos professores" [...] (Professor 2, 5, 6 e 10), [...] "o empenho do Colegiado de Curso" [...] (Professor 2, 5, 10 e 12), [...] "o apoio da direção do CCS" [...] (Professor 2, 10 e 12), [...] "o desejo de inovar e criar" [...] (Professor 12), o [...] "estímulo do grupo" [...] (Professor 4), a [...] "união do grupo" [...] (Professor 5), o [...] "apoio do Projeto UNI" [...] (Professor 9), a [...] "adesão dos docentes" [...] (Professor 6) e, principalmente, [...] "a vontade de mudar" [...] (Professor 5), juntamente com o [...] "trabalho coletivo com o mesmo ideal" [...] (Professor 6), além da união entre os professores do básico com os do profissionalizante e o importante apoio e empenho do Colegiado de Curso, da direção do CCS e do Projeto UNI.

No entanto, fatores como tempo para construção do Módulo, recursos humanos, recursos bibliográficos, estrutura da biblioteca do CCS/HU, estrutura física das salas de aula, atendimento da Documentação Científica, relação entre objetivos propostos e conteúdos, relação teoria-prática, tempo para estudo individual, tempo para avaliação diária com os docentes, troca de professores durante a implementação, o coordenador também implementando o Módulo, a indisponibilidade do professor convidado e a reação dos alunos frente à nova Metodologia, vieram dificultar a construção e implementação do novo currículo, impossibilitando um desempenho mais efetivo por parte dos docentes e levando-os a refletir sobre as condições adequadas de trabalho.

\section{Conclusão}

Os resultados obtidos no presente trabalho fornecem subsídios para concluirmos que a mudança curricular no Curso de Enfermagem, da Universidade Estadual de Londrina, se deu após inesgotáveis discussões e com 
o objetivo de formar o profissional de enfermagem capaz de atender às novas demandas do mercado de trabalho. Tal mudança, no entanto, foi acompanhada de dificuldades e facilidades, já listadas e discutidas neste capítulo, tendo a formação pedagógica importante papel nesse processo.

Percebemos, com isto, que a contínua superação de dificuldades é o caminho que se vislumbra para tornar o processo verdadeiramente efetivo.

Em síntese, "Aperfeiçoar o Módulo, refazendo-o, acrescentando e reformulando-o" (Professor 9), é tarefa contínua e progressiva dos docentes envolvidos nesta transformação curricular. Viabilizar condições estruturais, políticas e humanas para este trabalho árduo, é fator prioritário nesse processo. Desta forma, encontrando caminhos e edificando o já construído, poderemos ter a certeza de que a formação acadêmica transpasse os muros da universidade para se tornar uma realidade ativa, crítica e participativa no seu papel social.

\section{Referências}

BERBEL, N. A. N. Questões de Ensino. Notícia, Londrina, n. 3, out. 1996.

BRASIL. Ministério da Educação. Lei de Diretrizes e Bases da Educação Nacional. Lei no 9.394, de 20/12/ 1996. [Brasília: Senado, 1996].

\section{Brasiliense, 1989.}

O que é Participação? 6. ed. São Paulo:

CARVALHO, V.; CASTRO, I.B. Marco conceitual para o ensino e a pesquisa de enfermagem fundamental : um ponto de vista. Revista Brasileira de Enfermagem. Brasília, n.38, p. 76-86, jan./mar.,1985.

DIAS-DA-SILVA, M. H. G. F. O professor e seu desenvolvimento profissional: superando a concepção do algoz incompetente. Cadernos Cedes, Campinas, p. 45-56, 1998.

DIAZ BORDENAVE, J. E. Alguns Fatores Pedagógicos. Trad. Maria Tereza Grane. Revista Interamericana de Educação de Adultos, v.2, n. 1/2, 1983.
FLEURI, R. M. Educar para quê? 9. ed. São Paulo: Cortez, 1997.

FONTOURA, A. A Reforma do Ensino. Rio de Janeiro: Aurora, 1972.

FREIRE, P. Educação como prática da liberdade. 3. ed. Rio de Janeiro: Paz e Terra, 1971.

GARCIA, O. G. Duas horas semanais fazem a revolução? Revista de Educação AEC, ano 28, n. 111, p.73-82, 1999.

ITO, A. M. Y. PEEPIN: uma inovação no ensino das profissões de saúde. Semina: Ciênc. Biol. Saúde, Londrina, v. 15, p. 6-10, jun. 1994. Edição especial.

MATOS, J. C. Pensando a formação de professores. Revista de Educação, Brasília, v. 27, n.108, p.57-72, Jul./Set., 1998.

MINAYO, M.C.S. O desafio do conhecimento: pesquisa qualitativa em saúde. 3. ed. São Paulo: Hucitec, 1992.

PECCI, J. C. O ramo de hortênsias. São Paulo: Círculo do Livro, 1990.

PERRENOUD, P. Práticas pedagógicas. Lisboa: Dom Quixote, 1993.

PIMENTA, S. G. Saberes pedagógicos e atividade docente. São Paulo: Cortez, 1999.

PONCE, B. J. O professor pomo sujeito da ação social ou da urgente e necessária revitalização social da profissão docente. Revista de Educação, Brasília, v.26, n.104, p. 85-123, jul./set., 1997.

SOUZA, N. A. A avaliação da aprendizagem na construção do saber e do fazer docente. Marília, 1999. Tese (Doutorado em Educação) - Faculdade de Filosofia e Ciências. Universidade Estadual Paulista.

Sol e Sombra: a relação teoria-prática na formação do professor. Contexto e Educação, ljuí, ano 15, n. 58, p.25-41, abr./jun. 2000.

UNIVERSIDADE ESTADUAL DE LONDRINA (UEL). Colegiado do Curso de Enfermagem. Currículo Integrado de Enfermagem da Universidade Estadual de Londrina. Londrina: UEL, 1999. 